\title{
Three-dimensional geometry of coronary arteries after arterial switch operation for transposition of the great arteries and late coronary events
}

Clément Batteux, MD, ${ }^{\mathrm{a}}$ Samya Abakka, MD, ${ }^{\mathrm{a}}$ Régis Gaudin, MD, ${ }^{\mathrm{a}}$ Pascal Vouhé, MD, PhD, ${ }^{\mathrm{a}, \mathrm{b}}$

Olivier Raisky, $\mathrm{MD}, \mathrm{PhD},{ }^{\mathrm{a}, \mathrm{b}}$ and Damien Bonnet, $\mathrm{MD}, \mathrm{PhD}^{\mathrm{a}, \mathrm{b}}$

\section{ABSTRACT}

Objective: Using 3-dimensional (3D) modeling to predict late coronary events after the arterial switch operation (ASO) for transposition of the great arteries (TGA).

Method: We reviewed 100 coronary computed tomography scans performed after ASO randomly selected from free-from-coronary-event patients and 21 coronary computed tomography scans from patients who had a coronary event later than 3 years after ASO. Using 3D modeling software, we defined and measured 6 geometric criteria for each coronary artery: Clockwise position of coronary ostium, First centimeter angle defined as the angle between of the coronary artery ostium and the first centimeter of the vessel, Minimal 3D angle between the coronary first centimeter and the aortic wall, ostium height defined as the distance between the ostium and the aortic valve, distance between the coronary ostium and the pulmonary artery, and distance between the coronary first centimeter and the pulmonary artery.

Results: None of the right ostium geometric parameters were associated with coronary events. Four out of 6 criteria of left coronary artery geometry were associated to coronary events: Clockwise position of the left ostium $>67^{\circ}(P<.001)$, First centimeter angle $>62^{\circ}(P<.01)$, minimal $3 \mathrm{D}$ angle $<39^{\circ}(P=.003)$, distance between the coronary ostium and the pulmonary artery $<1 \mathrm{~mm} / \mathrm{mm}(P=.03)$. The association of first centimeter angle $>62^{\circ}$ and minimal angle in $3 \mathrm{D}<39^{\circ}$ had a $88 \%$ sensitivity and a $81 \%$ specificity to predict coronary events (receiver operator characteristics curve, 0.847; 95\% confidence interval, 0.745-0.949; $P<.001$ ).

Conclusions: The acquired geometric characteristics of the transferred left coronary artery are associated with coronary events. Imaging coronary arteries after ASO might be useful to select patients at higher risk of coronary events and to tailor surveillance. (J Thorac Cardiovasc Surg 2021;161:1396-404)

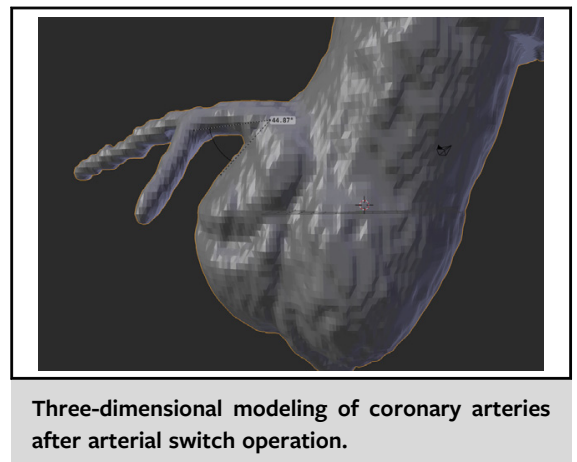

CENTRAL MESSAGE

Using imaging and 3D modeling of coronary arteries after ASO, we identified 4 left coronary anatomical/geometric criteria associated with coronary events.

\section{PERSPECTIVE STATEMENT}

Imaging and 3D modeling of coronary arteries after ASO might be useful to select patients at higher risk of coronary events and to tailor surveillance

See Commentaries on pages 1405 and 1406.
The arterial switch operation (ASO) is the current surgical treatment of transposition of the great arteries (TGA). Postoperative mortality and morbidity are essentially associated with the inherent risks of coronary artery transfer. ${ }^{1}$ The risk factors for coronary events after the ASO differ between reported series. $^{2-4}$ Preoperative coronary anatomy, great vessels spatial

From ${ }^{a}$ Department of Congenital and Pediatric Cardiology, Centre de Référence Malformations Cardiaques Congénitales Complexes, Hôpital Necker-Enfants Malades, Assistance Publique-Hopitaux de Paris, Paris, France; and ${ }^{\mathrm{b}}$ Université de Paris, Paris, France.

Supported by the Fondation Coeur et Artères and the Association pour la Recherche en Cardiologie du Foetus à l'Adulte.

Received for publication Sept 5, 2019; revisions received May 26, 2020; accepted for publication June 6, 2020; available ahead of print June 29, 2020.

Address for reprints: Clément Batteux, MD, Hôpital Necker-Enfants Malades, Pediatric and Congenital Cardiology, 149 rue de Sèvres, 75015 Paris, France (E-mail: Batteuxcl3ment@gmail.com).

$0022-5223 / \$ 36.00$

Copyright (c) 2020 by The American Association for Thoracic Surgery https://doi.org/10.1016/j.jtcvs.2020.06.036 relationship, and peroperative difficulties have been proposed as important predictors of late coronary artery obstruction. ${ }^{5,6}$

The need for systematic screening of postoperative coronary anatomy after the ASO for TGA remains debatable. Indeed, the number of late ischemic events later than 5 years after the ASO is low. ${ }^{8-11}$ A recent meta-analysis concluded that the rarity of coronary related events does not justify systematic screening for coronary obstruction. ${ }^{7}$ In addition, there is no defined management strategy when subclinical coronary anatomic or physiologic abnormalities are identified. Still,

- Scanning this $\mathrm{QR}$ code will take you to the table of contents to access supplementary information.

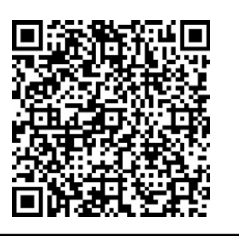




\section{Abbreviations and Acronyms \\ $3 \mathrm{D}=3$ dimensional \\ $\mathrm{ASO}=$ arterial switch operation \\ $\mathrm{AUC}=$ area under the curve \\ $\mathrm{CT}=$ computed tomography \\ LCA $=$ left coronary artery \\ $\mathrm{RCA}=$ right coronary artery \\ $\mathrm{TGA}=$ transposition of great arteries}

late coronary events do exist and the question is still pending on how to predict them and to identify patients at higher risk. Further, symptoms attributable to coronary obstructions can be atypical and defining more precisely the characteristics of patients at risk remains an important issue. Finally, the effects of acquired coronary artery disease superimposed on manipulated coronary arteries will not be known before the oldest patients reach the fourth or fifth decade. ${ }^{12}$

We have previously reported our strategy of screening for coronary artery obstruction after the ASO. ${ }^{13}$ It is indeed of note that the number of late coronary events in patients older than age 5 years are extremely rare. ${ }^{8-11}$ Hitherto, however, we have recently identified a subgroup of patients with anteriorly reimplanted left coronary artery (LCA) with a higher probability of perfusion abnormality. ${ }^{14}$ This finding is consistent with our previous report on the risk factors for early stenosis of the LCA. ${ }^{15}$

Here, we sought to determine whether there was a relationship between the 3-dimensional (3D) geometry of the reimplanted coronary arteries and coronary events after the ASO for TGA.

\section{METHODS}

\section{Coronary Events}

We defined coronary event as the occurrence of 1 of the following items.

- Sudden death proven to be related to coronary artery obstruction,

- Reoperation for coronary artery obstruction more than 3 years after the ASO (surgical or percutaneous),

- Occlusion or severe coronary artery stenosis $(>80 \%)$ identified in an asymptomatic patient (by magnetic resonance imaging, CT, or angiography), or

- Myocardial ischemia diagnosed on magnetic resonance imaging or myocardial perfusion scintigraphy associated with coronary artery obstruction $(<80 \%)$.

The coronary artery preoperative anatomy was classified according to the Yacoub and Radley-Smith and Leiden classifications. ${ }^{16}$

\section{Patients}

All patients who had a coronary event more than 3 years after the ASO for TGA between January 2000 and September 2018 were included in the study.

The comparison group was made of 100 randomly selected patients from our cohort of patients who had coronary CT after ASO for TGA at our institution between 2000 and 2012, and who were asymptomatic without any coronary event during their follow-up. All underwent systematic screening of reimplanted coronary arteries using CT between 4 and
6 years after the ASO. These 100 selected coronary CT were analyzed using the 3D modeling software.

In addition, we added a group of 10 non-TGA patients (mean age, 5.2 years) who had a normal coronary $\mathrm{CT}$ at our institution during this period who were in the same age range.

Patients with a single ostium were excluded from the study. Patients in whom the quality of the coronary $\mathrm{CT}$ did not allow adequate segmentation and 3D reconstruction were also excluded. This study obtained approval of our institution ethics review board for retrospective studies.

\section{Coronary CT Angiography}

Coronary CTs were performed with a 64-slice CT machine (LightSpeed VCT; GE Medical Systems, Milwaukee, Wis) with intravenous contrast enhancement. We performed retrospective electrocardiogram-gated acquisitions. Images were reconstructed at $75 \%$ of the R-R interval.

\section{Coronary Artery 3D-Segmentation and Postprocessing Software}

We used itk-snap (Paul A. Yushkevich, University of Pennsylvania, Philadelphia, Pa) as a segmentation software to 3D model coronary arteries, aorta, and pulmonary artery. Thresholding was the segmentation mode chosen to perform the 3D modeling. We used 2 postprocessing software to measure distances and angles: Meshmixer for distances, and Blender for angles (Video 1).

\section{Geometric Parameters of Coronary Artery Anatomy}

For each coronary artery, we defined and measured 6 items on the 3Dmodel (Figures 1-3).

Angles were in degrees and distances were in millimeters. Each item was blindly measured by 3 physicians ( 2 cardiologists and 1 radiologist) and the median value of the 3 measures was kept in analyses.

The clockwise position was defined as the angle between the ostium position on the aorta and a line passing through the center of the aorta in an axial view (Figure 2, $A$ ). The first centimeter angle was defined as the angulation of the course from the coronary ostium to the coronary artery first centimeter (Figure 2,B). The minimal 3D angle was defined as the minimal angle found on the 3D model between the coronary first centimeter and the aortic wall (Figure 2, C). The ostium height was defined as the distance between the ostium and the aortic valve (Figure $3, A$ ).

The distance between the coronary ostium and the pulmonary artery and the distance between the coronary first centimeter and the pulmonary artery were measured as shown on Figure 3, $B$ and $C$. All distances were adjusted with the aortic valve diameter.

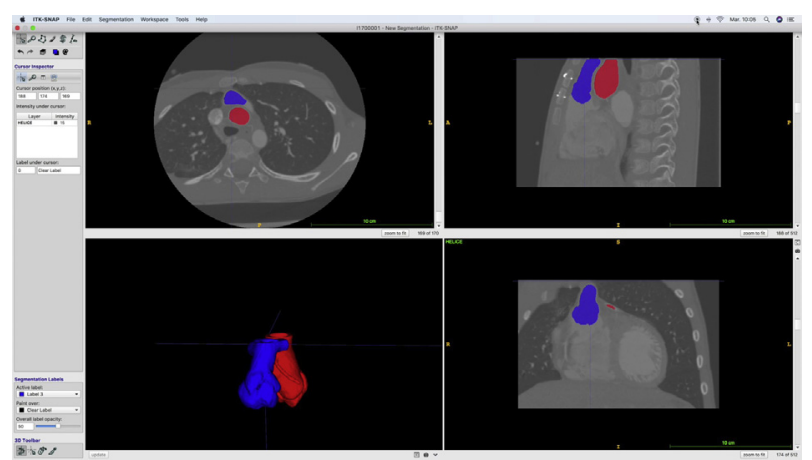

VIDEO 1. Coronary arteries and pulmonary trunk 3-dimensional modeling using 3-dimensional software. Video available at: https://www. jtcvs.org/article/S0022-5223(20)31757-8/fulltext. 


\begin{tabular}{|c|c|c|}
\hline $\begin{array}{c}100 \\
\text { free-from } \\
\text { coronary events }\end{array}$ & $\begin{array}{c}21 \\
\text { coronary events }\end{array}$ & $\begin{array}{c}10 \\
\text { controls }\end{array}$ \\
\hline
\end{tabular}

Coronary CT at 5 years of age

$3 \mathrm{D}$ modeling and geometric analysis

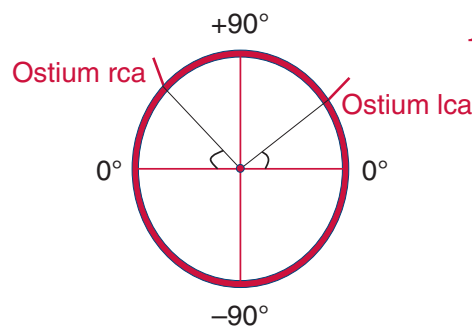

A

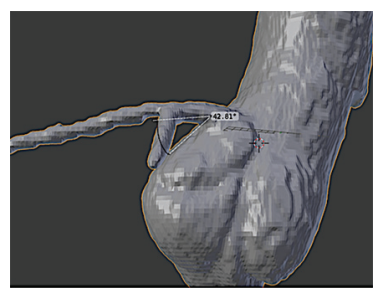

C

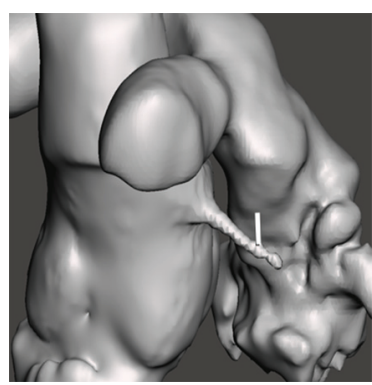

E

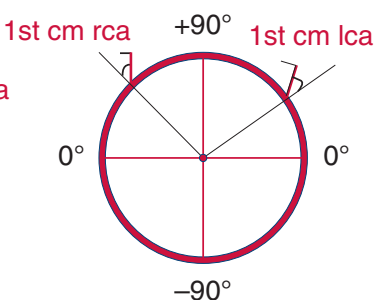

B

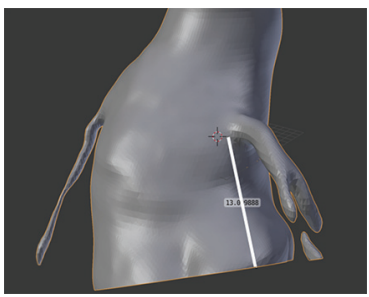

D

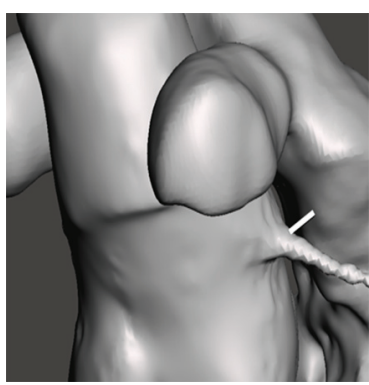

$\mathbf{F}$

Four geometric criteria of left coronary artery anatomy were associated with coronary events

1. Clockwise position of the left ostium $>67^{\circ}(P<.001)$

2. First centimeter angle $>62^{\circ}, P<.01$

3. Minimal 3D angle $<39^{\circ}, P=.003$

4. Distance between the coronary ostium and the pulmonary artery $<1 \mathrm{~mm} / \mathrm{mm}, P=.03$

Association of criteria $B+C$ had a $88 \%$ sensitivity and a $81 \%$ specificity

to predict coronary events.

FIGURE 1. A, Clockwise position. B, First centimeter angle. C, Minimal angle. D, Ostium high. E and F, Minimal distance separating coronary first centimeter $(E)$ and coronary ostium $(F)$ from the pulmonary artery. $C T$, Computed tomography; $3 D, 3$ dimensional.

\section{Statistical Analysis}

Coronary events were analyzed separately for right and left coronary artery. Each geometric criterion's association with coronary event was analyzed with binary logistic regression. To identify independent predictors of cardiac events, multivariable logistic regression analysis was performed by using variables that had been selected by univariable analysis. To predict which association is the most relevant to predict coronary events and establish a test, each criterion was tested alone then combined to others. The discriminatory capacity of the test was assessed using the area under the receiver operating characteristics curve. A probability value of $P<.05$ was required for entry into the test. The results are expressed as an odds ratio with a $95 \%$ confidence interval (CI). Statistical analyses were performed with IBM-SPSS software (IBM-SPSS Inc, Armonk, NY). 

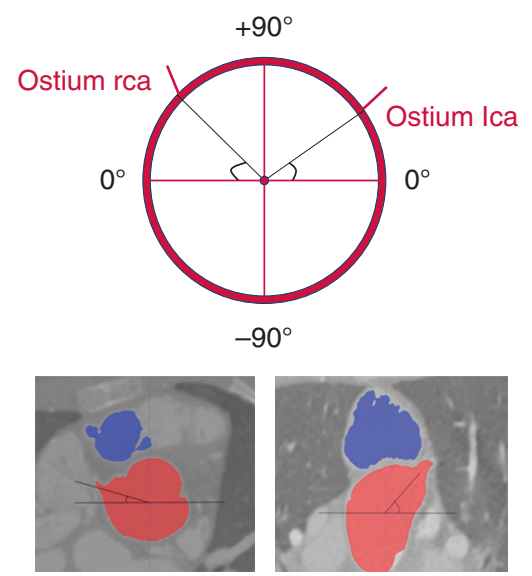

A
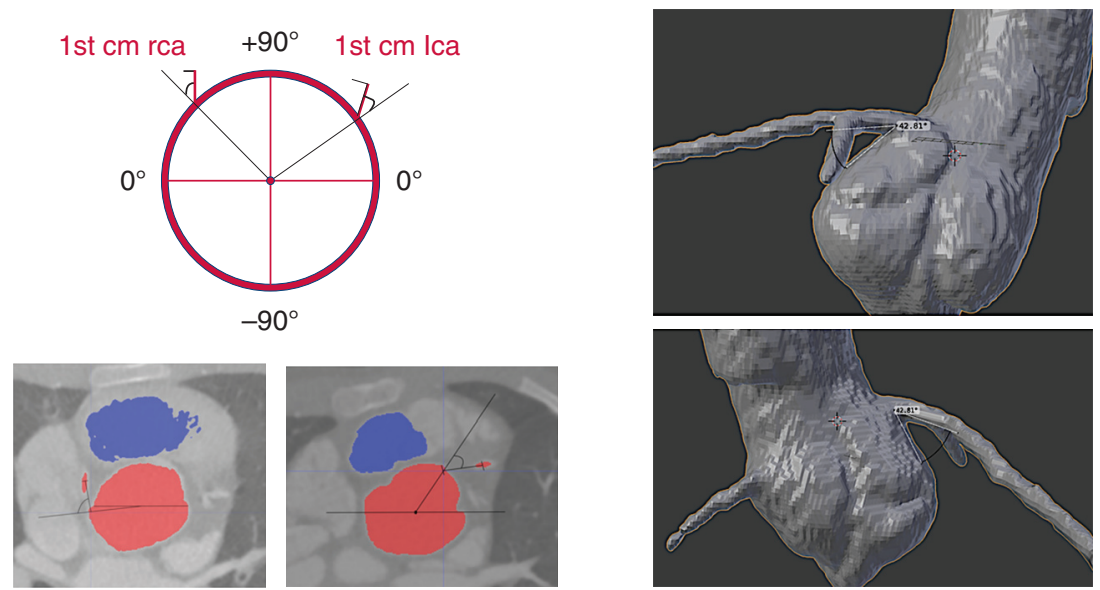

B

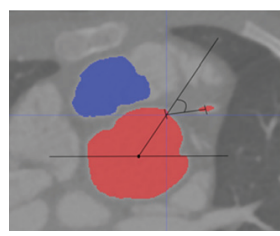

FIGURE 2. A, Clockwise position of the coronary ostium measured in a axial plan: Angle between the $0^{\circ}$ line passing through the center of the neo-aorta and each ostium (right coronary artery $[R C A]$ and left coronary artery $[L C A])$. Colors on computed tomography: Red, aorta and coronary artery; Blue, pulmonary trunk. B, Angle of coronary stem's first centimeter measured by the line passing through the center of the neo-aorta and each ostium and by the line passing through the ostium and the first centimeter. C, Coronary first centimeter minimal angulation with the aortic wall measured by 3-dimensional software.

\section{RESULTS}

\section{Patients}

Over the study period, approximately 1200 ASO for TGA were performed at our institution and around 750 had control coronary CT between 4 and 6 years of age. We randomly selected 100 patients from this cohort for $3 \mathrm{D}$ analysis. Of those 100 patients, 16 were excluded from the study because the initial anatomy was single ostium coronary artery in 6 and for poor quality of the CT in the remaining 10 patients. The acquisition in free breathing under sedation and with beta-blockers to slow heart rate is necessary to obtain a good quality coronary CT. The proportion of $10 \%$ with insufficient Digital Imaging and Communications in Medicine images quality is usual in our experience. Over the study period, we identified 21 patients with coronary events later than 3 years after an ASO related to LCA obstruction in 17 and right coronary artery (RCA) in 4. The preoperative coronary anatomy and the events are shown in Table 1. All patients with coronary obstruction and myocardial ischemia underwent surgical revascularization using mainly surgical repair of the left or the right coronary stem with saphenous or pericardial patch. Two patients had coronary bypass, 1 on the LCA and the second on the RCA. Patients who did not have myocardial ischemia at time of diagnosis of coronary obstruction were all treated with beta-blockers. Mean follow up for the free-from-event group was $9.4 \pm 3.8$ years.

\section{Geometric Parameters of Coronary Artery Anatomy}

In univariate analysis, 4 geometric criteria were associated with left coronary events: clockwise position $>67^{\circ}$ $(P<.001)$ (Figure 4, A), first centimeter angle $>62^{\circ}$ $(P<.01)$ (Figure 4, $B)$, minimal 3D angle $<39^{\circ}$ $(P=.003)$ (Figure 5, $A)$, and distance between the coronary ostium and the pulmonary artery $<0.1 \mathrm{~cm}(P=.03)$ (Figure 5, B). In multivariate analysis, first centimeter angle 

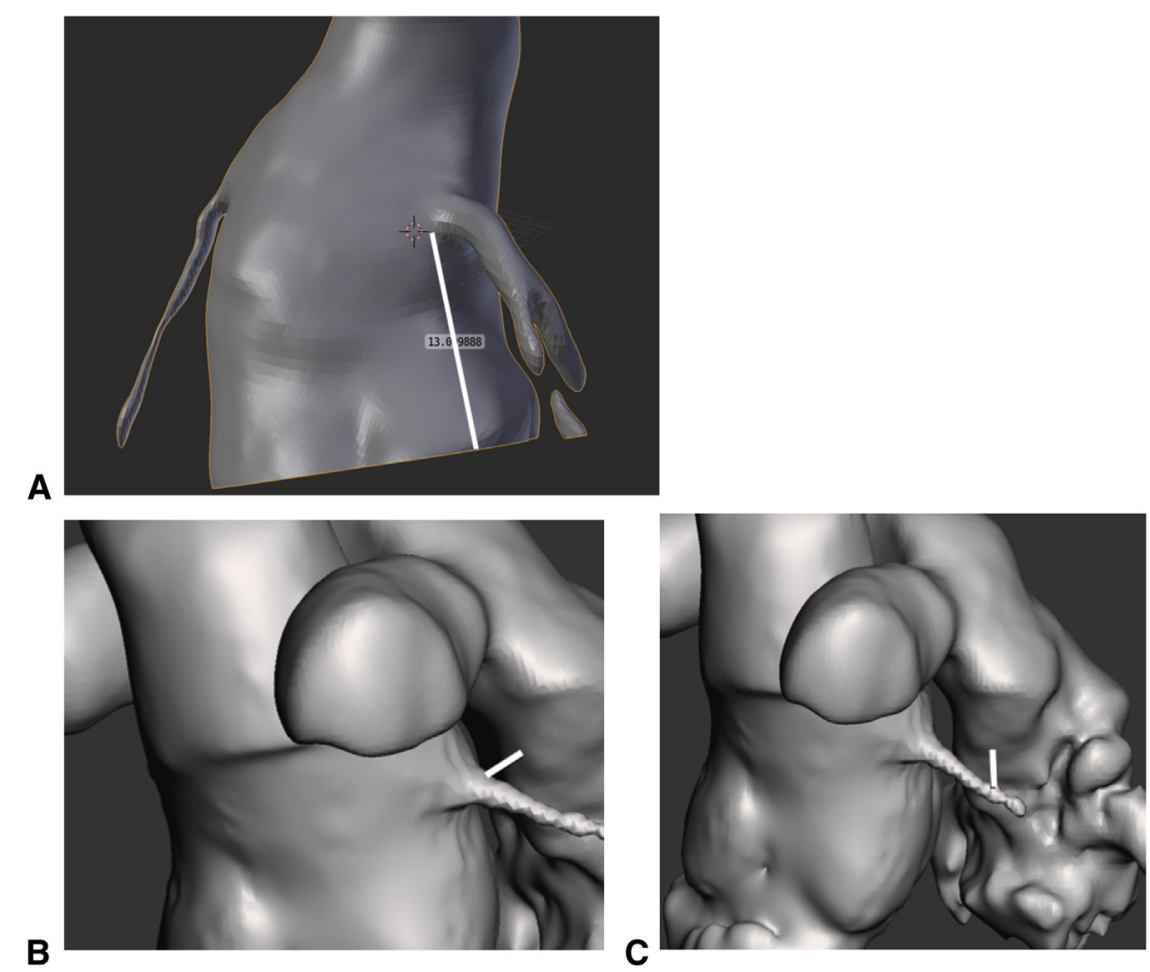

FIGURE 3. A, Height of coronary ostium reimplantation measured from the nadir of aortic cusps. B, Minimal distance separating coronary ostium from pulmonary artery. C, Minimal distance separating first coronary centimeter from pulmonary artery.

$>62^{\circ}$ was significantly associated with coronary event $(P=.028)$.

The sensitivity and specificity of the different geometric criteria and criteria combinations to predict association with coronary events are:

TABLE 1. Characteristics of patients

\begin{tabular}{lccc}
\hline \multicolumn{1}{c}{ Characteristic } & \multicolumn{2}{c}{$\begin{array}{c}\text { Coronary } \\
\text { events }(\mathbf{n}=\mathbf{2 1})\end{array}$} & $\begin{array}{c}\text { No coronary } \\
\text { events }(\mathbf{n}=\mathbf{8 4})\end{array}$ \\
\cline { 2 - 3 } & LCA & RCA & \\
\hline $\begin{array}{c}\text { Preoperative coronary } \\
\text { anatomy }\end{array}$ & & & \\
Yacoub (Leiden) & 8 & 2 & 60 \\
A (1LCx 2R) & 5 & 1 & 4 \\
C (1LCx 2R) & 4 & 1 & 17 \\
D (1L 2RCx) & 0 & 0 & 3 \\
E (1R 2LCx) & $6.3 \pm 2.2$ & & $5.8 \pm 1.6$ \\
Age at coronary CT (y) & $8.9 \pm 3.8$ & & NA \\
Age at coronary event (y) & & & NA \\
Type of coronary event & 1 & 0 & \\
Death & 3 & 1 & \\
Re-intervention for CA & & & \\
$\quad$ obstruction & 8 & 2 & \\
CA occlusion or stenosis & & & \\
$\quad>80 \%$ & 5 & 1 & \\
Myocardial ischemia &
\end{tabular}

Values are presented as $\mathrm{n}$ or mean \pm standard deviation. $L C A$, Left coronary artery; $R C A$, right coronary artery; $C T$, computed tomography; $N A$, not applicable; $C A$, coronary artery.
- Clockwise position $>67^{\circ}$. Sensitivity, 0.77; specificity, 0.84; area under the curve (AUC), 0.8 ; 95\% CI, 0.6740.926; $P<.001$ (Figure 4, A);

- First centimeter angle $>62^{\circ}$. Sensitivity, 0.94; specificity, 0.7 AUC, $0.82 ; 95 \%$ CI, 0.723-0.912; $P<.001$ (Figure 4, B);

- Minimal angle $<39^{\circ}$. Sensitivity, 0.88 ; specificity, 0.63; AUC, 0.75; 95\% CI, 0.645-0.872; $P=.03$ (Figure 5, $A$ );

- Distance coronary ostium-pulmonary artery $<0.1$. Sensitivity, 0.65; specificity, 0.73; AUC, 0.8 ; 95\% CI, 0.545$0.831 ; P=.03$ (Figure $5, B$ ); and

- The association of first centimeter angle $>62^{\circ}$ and minimal 3D angle $<39^{\circ}$ had the highest sensitivity $(0.88)$ and specificity $(0.81)$ for the association with coronary events (AUC, 0.85, 95\% CI, 0.745-0.949; $P<.001$ (Figure 6).

There was no role of the presence of an anterior or posterior loop of 1 of the left coronary branches in the measurements of the different geometric parameters that were limited to the first centimeter.

\section{Group Description}

As shown in Table 2, In our cohort of 17 LCA events patients, 13 out of $17(76 \%)$ patients had the clockwise angle $>67^{\circ}, 16$ out of $17(94 \%)$ had the first centimeter angle $>62^{\circ}, 15$ out of $17(88 \%)$ patients had the minimal angle $<39^{\circ}, 11$ out of $17(64 \%)$ patients had the coronary ostium 
Clockwise position $>67^{\circ}$. Sensitivity 0.77 , specificity 0.84 .
AUC $0.8,95 \% \mathrm{Cl}(0.674-0.926), P<.001$.

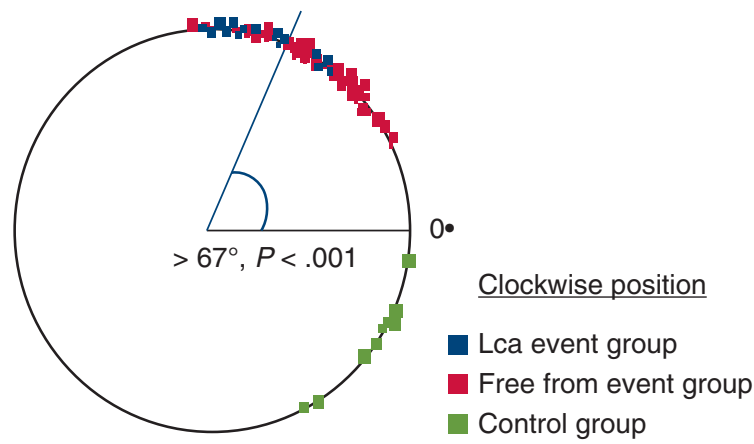

A

LCA 1 st $\mathrm{cm}$ angle

First centimeter angle $>62^{\circ}$. Sensitivity 0.94 , specificity 0.7 .

AUC $0.82,95 \% \mathrm{Cl}(0.723-0.912), P<.001$.

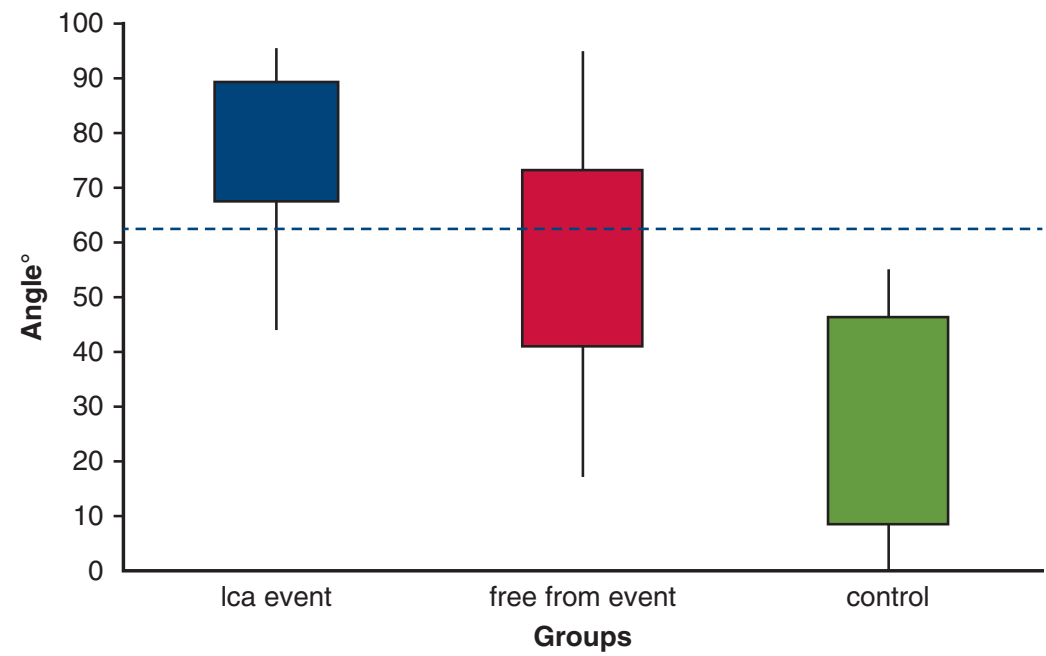

B

FIGURE 4. A, left coronary artery ( $L C A$ ) clockwise position (red line $67^{\circ}$, red points indicate event group, black points indicate free from event group, and green points indicate control group). B, First stem centimeter angle (above red dotted line angle $>62^{\circ}$, red box plot indicates event group, blue box plot indicates free from event group, and green box plot indicates control group). AUC, Area under the curve; $C I$, confidence interval.

distance from pulmonary artery $<0.1$. Finally, 15 out of 17 patients $(88 \%)$ had the combination first centimeter angle $>62^{\circ}$ and minimal angle $<39^{\circ}$.

In our cohort of 88 free-from LCA events patients, 17 out of $88(19 \%)$ patients had the clockwise angle $>67^{\circ}, 29$ out of $88(33 \%)$ had the first centimeter angle $>62^{\circ}, 32$ out of $88(36 \%)$ patients had the minimal angle $<39^{\circ}, 24$ out of 88 $(27 \%)$ patients had the coronary ostium distance from pulmonary artery $<0.1 \mathrm{~mm} / \mathrm{mm}$.

Fifteen out of 88 patients $(17 \%)$ had the combination first centimeter angle $>62^{\circ}$ and minimal angle $>39^{\circ}$.

None of the geometric criterion for the RCA was associated with the 4 coronary events related to the RCA obstruction.

\section{DISCUSSION}

Coronary artery obstruction late after the ASO has a genuinely low rate and is more frequently anatomic than physiologic. ${ }^{17-19}$ Freedom from coronary events in adults after ASO is higher than $95 \%$ in the majority of series. ${ }^{8-11}$ Considering the fact that patients with ASO and denervated coronary arteries may not experience typical symptoms of angina, routine screening for coronary obstruction during follow-up is often performed to identify potential lesions of concern. ${ }^{20}$ Echocardiogram-gated CT angiography provides excellent spatial resolution to evaluate the coronary arteries and is considered by many the technique of choice for morphologic assessment as indeed, clinical evaluation, electrocardiography, and 
LCA minimal angle

Minimal angle $<39^{\circ}$. Sensitivity 0.88 , specificity 0.63 AUC $0.75,95 \% \mathrm{Cl}(0.645-0.872), P=.03$

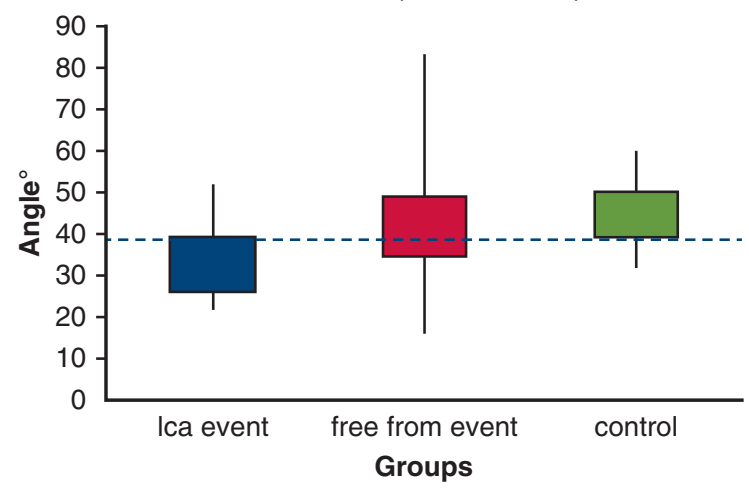

A

Distance coronary ostium-pulmonary artery $<0,1$. Sensitivity 0.65 , specificity 0.73 AUC $0.8,95 \% \mathrm{Cl}(0.545-0.831), P=.03$

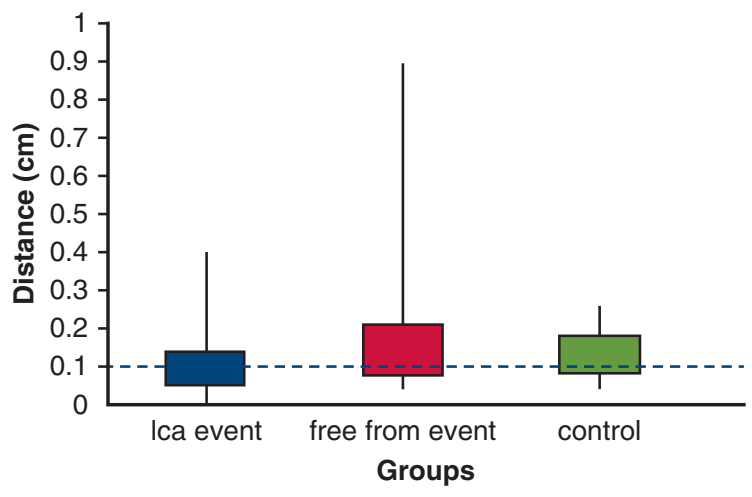

B

FIGURE 5. A, Left coronary artery ( $L C A$ ) minimal angle (below red dotted line angle $<39^{\circ}$, red box plot indicates event group, blue box plot indicates free from event group, green box plot indicates control group). B, Distance coronary ostium - pulmonary artery (below red dotted line indicates distance $<0.1$, red box plot indicates event group, blue box plot indicates free from event group, and green box plot indicates control group). $A U C$, Area under the curve; $C I$, confidence interval.

echocardiography have a low sensitivity for detecting coronary insufficiency. ${ }^{13}$ Although coronary obstruction have been found in asymptomatic patients with ASO in various studies, a recent meta-analysis showed that routine coronary imaging is not justified to prevent coronary events in the long term. ${ }^{7}$ These results should lead to modify the current guidelines that suggest screening patients with ASO for coronary anomalies exposing them to radiation. ${ }^{21}$ Nevertheless, coronary events do occur late after the ASO and the identification of high-risk subgroups that may benefit from coronary surveillance remains a contentious issue.

Risk factors for coronary events have been extensively described and are mainly related to preoperative coronary

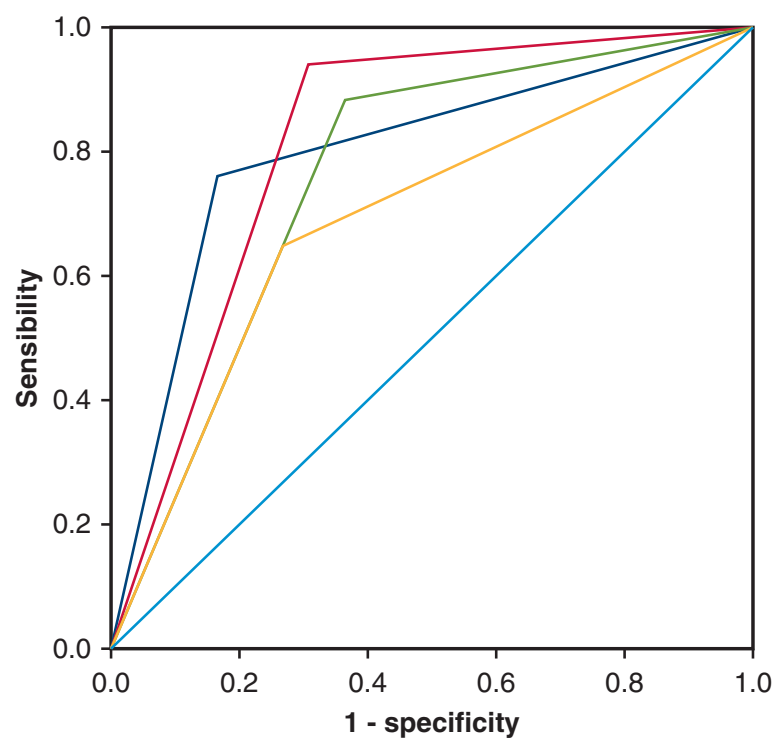

- A. Clockwise (AUC 0.8)

- B. 1st cm angle (AUC 0.818)

- C. Minimal angle (AUC 0.759)

- D. Distance ostium-PA (AUC 0.688)



\begin{tabular}{|c|c|c|c|}
\hline \multicolumn{4}{|c|}{ AUC } \\
\hline$-A B$ & 0.818 & $-\mathrm{ABC}$ & 0.812 \\
\hline$A C$ & 0.806 & $-\mathrm{ACD}$ & 0.706 \\
\hline$-A D$ & 0.724 & $-\mathrm{ABD}$ & 0.735 \\
\hline$B C$ & 0.847 & $-B C D$ & 0.753 \\
\hline $\mathrm{BD}$ & 0.765 & $-\mathrm{ABCD}$ & 0.712 \\
\hline 0 & 0.735 & - & \\
\hline
\end{tabular}

FIGURE 6. Receiver operator characteristics curves of each significant criteria alone (above) and all combinations possible of significant criteria (below). AUC, Area under the curve; $C I$, confidence interval. 
TABLE 2. Results for all significant criteria (subgroup analysis)

\begin{tabular}{lcc}
\hline \multicolumn{1}{c}{ Geometric factors } & $\begin{array}{c}\text { Event group } \\
\text { for LCA } \\
(\mathbf{n}=\mathbf{1 7})\end{array}$ & $\begin{array}{c}\text { Free from } \\
\text { LCA-related } \\
\text { event group } \\
(\mathbf{n}=\mathbf{8 8})^{*}\end{array}$ \\
\hline Clockwise $>67^{\circ}$ & $13(76)$ & $17(19)$ \\
\hline First centimeter angle $>62^{\circ}$ & $16(94)$ & $29(33)$ \\
\hline Minimal angle $<39^{\circ}$ & $15(88)$ & $32(36)$ \\
$\begin{array}{l}\text { Distance ostium to pulmonary } \\
\text { artery }<0.1 \mathrm{~cm}\end{array}$ & $11(64)$ & $24(27)$ \\
\hline $\begin{array}{l}\text { First centimeter angle } \\
>62^{\circ}+\text { minimal } \\
\text { angle }<39^{\circ}\end{array}$ & $15(88)$ & $15(17)$ \\
\hline
\end{tabular}

Values are presented as $\mathrm{n}(\%) . L C A$, Left coronary artery. *Eighty-four patients from the randomly selected group of transposition of the great arteries patients with the addition of the 4 patients who had a coronary event related to right coronary artery obstruction.

anatomy..$^{8-11,13}$ The acquired anatomy of the coronary artery is a potential risk factor for late coronary events because the initial course is usually abnormal in relation with the arterial switch technique. ${ }^{22,23}$ Here, we sought to analyze the 3D acquired morphology of the initial segments of coronary artery after ASO and we found that the position of the reimplanted left ostium as well as the development of an acute angle between the ostium and the epicardial part of the left coronary artery was associated with coronary obstruction or clinical events. In addition, the short distance between the left coronary artery and the pulmonary artery was also associated with coronary events.

We believe that these anatomical characteristics identify a subgroup of patients at higher risk of late coronary events. The progressive dilatation of the aortic root that is currently observed in ASO could contribute to elongate the coronary arteries and promote the development of an acute angle of the coronary origin. ${ }^{24}$ The same hypothesis applies to the height of the takeoff of the RCA even if we did not find any association between the RCA 3D anatomy and coronary events probably because the number of events was too low. In addition, the close vicinity with the pulmonary artery after the Lecompte maneuver, could lead to compression of the coronary arteries by the pulmonary arteries and in this case, exercise could induce ischemia. ${ }^{25}$ The proportion of patients with these at-risk anatomical characteristics of left ostium represent a limited number of ASO patients and this may explain the low prevalence of coronary events after ASO. However, if screening might not be useful to predict late coronary events in the whole population after ASO, it might be of importance to identify this subgroup of patients who will need tailored surveillance. We suggest here that imaging the coronary arteries and measuring these parameters could limit follow-up for late coronary obstruction to the subgroup of patients who had these geometric characteristics. Potentially, perfusion study using cardiac magnetic resonance imaging could be proposed to this selected group of patients during long-term follow-up.

Some similarities and common uncertainties could be found with abnormal origin of the coronary artery from the opposite ostium. ${ }^{26,27}$ Of note, the exact pathophysiological mechanism for sudden cardiac events in these congenital anomalies of the coronary artery origin is unknown. The different hypotheses include intermittent compression of the coronary as it travels between the aorta and the pulmonary artery, and morphological alterations of the ostium of the anomalous vessel due to its tangential course along the aorta. An abnormal elliptical-shaped ostium has been observed by intravascular ultrasound studies in ASO and could correspond to a slit-like ostium. ${ }^{28}$ In addition, intimal proliferation is frequent in the proximal segment of the coronary arteries after ASO and it reduces the surface of the initial segment. ${ }^{28}$ These findings could suggest that the subgroup of patients that we identified have a disturbed flow at the origin of their coronary arteries that may promote late atherosclerosis.

How these findings may influence the surgical technique for reimplantation of the coronary arteries during the ASO for TGA is a difficult issue. Undeniably, at the time of ASO, the site of coronary reimplantation is dictated by the anatomic situation rather than by the choice of the surgeon. Several factors should be taken into consideration to adequately reimplant the coronary arteries: the height of the native coronary ostium, the length of the initial coronary segment (main left coronary stem before its first bifurcation), size discrepancy between the aorta and the pulmonary artery, proximal coronary branches which cannot be sacrificed, and the degree of misalignment of the valvular commissures. The implications of our study for the surgeon suggest that the coronary reimplantation should be performed not too medially to avoid compression of the coronary artery between the aorta and the pulmonary artery, and not too high to prevent progressive modification of the takeoff angulation due to dilatation of the corresponding sinus of Valsalva. It is of note that the surgical technique at time of the ASO might not be the only factor causing late coronary obstruction. Indeed, stretching of the initial segment may cause intimal proliferation and progressive dilatation and rotation of the neoaortic root can also modify the initial relationship between the coronary first centimeter and the great vessels.

The major limit of our study is that late follow-up of our study population is not available presently. We observed an association between some anatomical parameters and the presence of coronary events but we will need to apply these criteria in the whole ASO population of our institution to demonstrate that these criteria predict late events. In addition, the influence on surgical technique of coronary transfer is limited because the surgeons already do their best to limit sharp angulation of coronary artery stems. 
Routine imaging of coronary artery after the ASO has should not have the unique objective to detect coronary artery obstruction but should be used to identify a high-risk group of patients with an acute angle of the coronary origin and/or a partial inter-aortopulmonary course. This subgroup of patients may benefit of a tailored monitoring of coronary events with growth and aging. Conversely, those without these anatomical characteristics could be considered at very low risk of late coronary events.

\section{CONCLUSIONS}

In this study, we identified 4 anatomical geometric parameters describing the spatial position of the coronary arteries in relation with the great arteries after ASO that are associated with late coronary events. We believe that systematic imaging of coronary arteries after the ASO should aim to identify these anatomical characteristics and not only coronary obstruction to tailor follow-up.

\section{Conflict of Interest Statement}

The authors reported no conflicts of interest.

The Journal policy requires editors and reviewers to disclose conflicts of interest and to decline handling or reviewing manuscripts for which they may have a conflict of interest. The editors and reviewers of this article have no conflicts of interest.

\section{References}

1. Prêtre R, Tamisier D, Bonhoeffer P, Mauriat P, Pouard P, Sidi D, et al. Results of the arterial switch operation in neonates with transposed great arteries. Lancet. 2001;357:1826-30

2. Legendre A, Losay J, Touchot-Koné A, Serraf A, Belli E, Piot JD, et al. Coronary events after arterial switch operation for transposition of the great arteries. Circulation. 2003;108(Suppl 1):II186-90.

3. Moll M, Michalak KW, Sobczak-Budlewska K, Moll JA, Kopala M, Szymczyk K, et al. Coronary artery anomalies in patients with transposition of the great arteries and their impact on postoperative outcomes. Ann Thorac Surg. 2017;104:1620-8.

4. Al Anani S, Fughhi I, Taqatqa A, Elzein C, Ilbawi MN, Polimenakos AC. Transposition of great arteries with complex coronary artery variants: time-related events following arterial switch operation. Pediatr Cardiol. 2017;38:513-24.

5. Pasquali SK, Hasselblad V, Li JS, Kong DF, Sanders SP. Coronary artery pattern and outcome of arterial switch operation for transposition of the great arteries: a meta-analysis. Circulation. 2002;106:2575-80.

6. Massoudy P, Baltalarli A, de Leval MR, Cook A, Neudorf U, Derrick G, et al. Anatomic variability in coronary arterial distribution with regard to the arterial switch procedure. Circulation. 2002;106:1980-4.

7. van Wijk SWH, van der Stelt F, Ter Heide H, Schoof PH, Doevendans PAFM, Meijboom FJ, et al. Sudden death due to coronary artery lesions long-term after the arterial switch operation: a systematic review. Can J Cardiol. 2017;33: 1180-7.

8. Tobler D, Williams WG, Jegatheeswaran A, Van Arsdell GS, McCrindle BW, Greutmann M, et al. Cardiac outcomes in young adult survivors of the arterial switch operation for transposition of the great arteries. J Am Coll Cardiol. 2010;56:58-64.

9. Lalezari S, Bruggemans EF, Blom NA, Hazekamp MG. Thirty-year experience with the arterial switch operation. Ann Thorac Surg. 2011;92:973-9.
10. Khairy P, Clair M, Fernandes SM, Blume ED, Powell AJ, Newburger JW, et al. Cardiovascular outcomes after the arterial switch operation for d-transposition of the great arteries. Circulation. 2013;127:331-9.

11. Kempny A, Wustmann K, Borgia F, Dimopoulos K, Uebing A, Li W, et al. Outcome in adult patients after arterial switch operation for transposition of the great arteries. Int J Cardiol. 2013;167:2588-93.

12. Villafañe J, Lantin-Hermoso MR, Bhatt AB, Tweddell JS, Geva T, Nathan M, et al. D-transposition of the great arteries: the current era of the arterial switch operation. J Am Coll Cardiol. 2014;64:498-511.

13. Bonhoeffer P, Bonnet D, Piéchaud JF, Stümper O, Aggoun Y, Villain E, et al. Coronary artery obstruction after the arterial switch operation for transposition of the great arteries in newborns. J Am Coll Cardiol. 1997;29:202-6.

14. Raimondi F, Aquaro GD, De Marchi D, Sandrini C, Khraiche D, Festa P, et al. Cardiac magnetic resonance myocardial perfusion after arterial switch for transposition of great arteries. JACC Cardiovasc Imaging. 2018;11:778-9.

15. Ou P, Khraiche D, Celermajer DS, Agnoletti G, Le Quan Sang KH, Thalabard JC, et al. Mechanisms of coronary complications after the arterial switch for transposition of the great arteries. J Thorac Cardiovasc Surg. 2013;145:1263-9.

16. Yacoub MH, Radley-Smith R. Anatomy of the coronary arteries in transposition of the great arteries and methods for their transfer in anatomical correction. Tho$\operatorname{rax} .1978 ; 33: 418-24$.

17. Hauser M, Bengel FM, Kuhn A, Sauer U, Zylla S, Braun SL, et al. Myocardial blood flow and flow reserve after coronary reimplantation in patients after arterial switch and ross operation. Circulation. 2001;103:1875-80.

18. Vogel M, Smallhorn JF, Gilday D, Benson LN, Ash J, Williams WG, et al. Assessment of myocardial perfusion in patients after the arterial switch operation. J Nucl Med. 1991;32:237-41.

19. Hayes AM, Baker EJ, Kakadeker A, Parsons JM, Martin RP, Radley-Smith R, et al. Influence of anatomic correction for transposition of the great arteries on myocardial perfusion: radionuclide imaging with technetium-99m 2-methoxy isobutyl isonitrile. J Am Coll Cardiol. 1994;24:769-77.

20. Kondo C, Nakazawa M, Momma K, Kusakabe K. Sympathetic denervation and reinnervation after arterial switch operation for complete transposition. Circulation. 1998:97:2414-9.

21. Sarris GE, Balmer C, Bonou P, Comas JV, da Cruz E, Di Chiara L, et al. Clinical guidelines for the management of patients with transposition of the great arteries with intact ventricular septum. Cardiol Young. 2017;27:530-9.

22. Li J, Tulloh RM, Cook A, Schneider M, Ho SY, Anderson RH. Coronary arterial origins in transposition of the great arteries: factors that affect outcome. A morphological and clinical study. Heart. 2000;83:320-5.

23. Ntsinjana HN, Capelli C, Biglino G, Cook AC, Tann O, Derrick G, et al. 3D morphometric analysis of the arterial switch operation using in vivo MRI data. Clin Anat. 2014;27:1212-22.

24. Veltman CE, Beeres SLMA, Kalkman DN, Kelder TP, Kiès P, Vliegen HW, et al. Variation in coronary anatomy in adult patients late after arterial switch operation: a computed tomography coronary angiography study. Ann Thorac Surg. 2013;96:1390-7.

25. Gatlin S, Kalynych A, Sallee D, Campbell R. Detection of a coronary artery anomaly after a sudden cardiac arrest in a 17 year-old with D-transposition of the great arteries status post arterial switch operation: a case report. Congenit Heart Dis. 2011;6:384-8.

26. Basso C, Maron BJ, Corrado D, Thiene G. Clinical profile of congenital coronary artery anomalies with origin from the wrong aortic sinus leading to sudden death in young competitive athletes. J Am Coll Cardiol. 2000;35:1493-501.

27. Erez E, Tam VK, Doublin NA, Stakes J. Anomalous coronary artery with aortic origin and course between the great arteries: improved diagnosis, anatomic findings, and surgical treatment. Ann Thorac Surg. 2006;82:973-7.

28. Pedra SRFF, Pedra CAC, Abizaid AA, Braga SLN, Staico R, Arrieta R, et al. Intracoronary ultrasound assessment late after the arterial switch operation for transposition of the great arteries. J Am Coll Cardiol. 2005;45:2061-8.

Key Words: congenital heart disease, transposition of great arteries, arterial switch operation, coronary transfer, 3 dimensional, 3D modeling 